\title{
Implementation of Dynamic Tariffs in the Portuguese Electricity System - Preliminary Results of a Cost- Benefit Analysis
}

\author{
J. T. Saraiva, J. N. Fidalgo, R. B. Pinto, R. Soares \\ DEEC/FEUP - Faculdade de Engenharia da Univ. do Porto \\ Rua Dr. Roberto Frias, 4200465 Porto, Portugal \\ jsaraiva@fe.up.pt,jfidalgo@fe.up.pt,rbpinto@inesctec.pt
}

\begin{abstract}
The current Portuguese Tariff Code dates from December 2014 and requires that the Distribution Network Operators (DSO), submit to the Portuguese Energy Services Regulatory Agency, ERSE, a plan for a pilot experiment and a Cost Benefit Analysis (CBA) regarding the introduction of dynamic options in the Access Tariffs in Portugal. In view of this request, EDP Distribuição, the main Portuguese DSO, established a contract with INESC TEC to conduct these studies and to prepare a report to submit to ERSE by June 2016. In this scope, this paper reports the results obtained so far namely regarding the $\mathrm{CBA}$ analysis. This analysis includes the identification of critical hours during which dynamic tariffs can be activated, the estimate of the impact of demand transfers to adjacent hours on the electricity market Social Welfare Function, on network losses, on the investment network avoided costs due to the possible deferral of reinforcements or expansions and on the costs of contracting reserves. These items were estimated along a period of 15 years and together with the estimate of the implementation costs of dynamic tariffs were used to conduct the mentioned CBA analysis.
\end{abstract}

Index Terms-Dynamic Tariffs, Access Tariffs, Cost Benefit Analysis, Regulation.

\section{INTRODUCTION}

The Portuguese power system started being restructured back in 1995, when a new legal framework was passed. By then, the system was organized in a market driven subsystem and in a public service driven subsystem. This public service subset was framed by long term contracts between generation companies and the transmission system operator, on one side, and also by regulated contracts between end users and distribution companies. By that time it was expected a gradual transition of clients from the public service system to the market. Also, generation companies would gradually accept ending the long term contracts and moving to the market. However, this smooth transition hardly occurred and in 2006 a new electricity law was passed in view of the implementation of a common electricity market with Spain. The new law recognized four main activities: generation, transmission, distribution and retail. Generation is now

\author{
J. Santos Afonso, G. Pires \\ EDP Distribuição SA \\ Rua Camilo Castelo Branco,43, 1050044 Lisboa, Portugal \\ JoseSantos.Afonso@edp.pt, Guido.Pires@edp.pt
}

organized in normal regime bidding at the daily market or establishing bilateral contracts and in special regime in which eligible stations and technologies receive feed-in tariffs, transmission and distribution are natural monopolies, in the form of regulated concessions, while retail is provided under a competitive regime.

In the scope of the mentioned restructuring process, ERSE was created in 1997. In 1998, the first Tariff Code was published setting the tariff structure for the 1999 - 2001 regulatory period. The Portuguese Tariff System is additive, and remained remarkably stable for the last 18 years. It contains a number of activity elementary tariffs and, based on their addition, composite or second level tariffs are obtained. Among the elementary tariffs, there are the Energy Tariff (ET), the Tariff for the Use of the Transmission Network (TUTN), the Tariff for the Use of the Distribution Network (TUDN), the Supply Tariff (ST) and the Tariff for the Global Use of the System (TGUS). The TGUS includes the costs with the system operator, the acquisition of secondary and tertiary reserves, the costs with the feed-in tariffs paid to the special regime generation and the subsidies given to the power companies of two Portuguese archipelagos. All together, the TUTN, the TUDN and TGUS form the Network Access Tariff. By summing up the Access Tariff, the ET and the ST, we obtain the tariff paid by the regulated end user clients. Network Access tariffs are paid through four terms: contracted power, active energy, reactive energy and average power during peak hours. The active energy term is priced according to four periods: peak, full, valley and super-valley.

Since 1998, power-related terms have been mostly used to recover network costs, that is, the regulated revenues of network providers are recovered using capacity-based terms, namely contracted power and average peak hour load, with the justification that these variables and prices are more directly related to investment network costs. The current peak period includes approximately 980 hours along the year and in each month the energy consumed in the peak period is summed up and divided by the number of peak hours in that month, leading to the average power in the peak period, 
which is finally multiplied by the corresponding price.

However, the Regulatory Agency considers that the current number of peak hours, 980 as mentioned above, is too large and that network investments are justified by the demand in a much smaller number of hours. On the other hand, the increasing distributed generation connected to distribution networks eventually leads to a mismatch between the peak hours in use and the periods of network demand.

Bearing this in mind and assuming that in the near future more distributed generation will be connected and that the number of electric vehicles rapidly increases, the Regulatory Agency required the distribution network operators to prepare a plan to introduce dynamic options in the tariff system. The current version of the Tariff Code establishes that distribution operators must submit, by June 2016, a plan to implement a number of pilots together with a Cost-Benefit Analysis, $\mathrm{CBA}$, regarding the introduction of dynamic tariffs. Despite being a responsibility of distribution operators, this CBA should estimate the costs and the benefits for the entire power system and not just at the distribution level.

As such, EDP Distribuição and the Centre for Power and Energy Systems of INESC TEC established a consultancy contract to develop the mentioned Cost-Benefit Analysis, $\mathrm{CBA}$, and to design and implement the dynamic tariff pilot experiments. This CBA Analysis has been concluded [1], and a document establishing the design and implementation rules for the dynamic tariffs (due by the end of June 2016) is being prepared. If approved, the pilot experiments will be implemented in the second half of 2016.

This paper reports the experience gained so far with the CBA Analysis, including its main assumptions and main results for several components. This includes the estimation of benefits from shifting demand from peak to off-peak hours in terms of the market Social Welfare Function, the gains from the expected decrease network losses and from network investment deferrals, as well as the benefits related with the cost of reserves, namely secondary reserve. Regarding the costs, the analysis considered estimates of software development costs to bill and notify the consumers, as well as the forecasting tool to be used to inform customers about the critical days/hours in advance.

Accordingly, after this initial section, Section II briefly describes the approaches available in the literature regarding dynamic tariffs as well as some international experiences on this topic. Section III provides details regarding the CBA analysis and Section IV summarizes the results obtained so far. Finally, Section V draws the most relevant conclusions.

\section{DYNAMIC TARIFFS - AVAILABLE APPROACHES AND INTERNATIONAL EXPERIENCIES}

\section{A. Available approaches in the literature}

The initial references to dynamic tariffs are from 90th of last century. In this scope, [2] indicates that "real time pricing, spot pricing and day ahead dynamic pricing and other similar tariffs have been proposed as a rational mechanism of load management, and the recent trend towards de-regulation and enhanced competition on the supply side also requires flexible methods for setting power contracts and prices". This papers also mentions that the electricity markets that started to be developed by then were essentially asymmetric given the reduced elasticity of demand, and that this was one of the major problems preventing true competition. Therefore, the adoption of mechanisms to promote demand flexibility would contribute to better balance the relation between generation agents and the demand.

In recent years, the increasing level of generation connected to distribution networks, the expected increase of the number of EV's and the progressive wide spread installation of smart meters is justifying and inducing a renewed interest in this topic. In general, Dynamic Tariffs [3] correspond to tariff options in which some variables, as the price and the application period, change more frequently and in a way that is not entirely defined or set when the tariffs are published, as compared with traditional tariffs. In this sense, it is important to distinguish Dynamic Tariffs in the way we are using in this paper from Time of Use (ToU) Tariffs [4]. ToU Tariffs are used in several countries and correspond to static tariffs, in the sense that, although displaying variations along the day/week or month, the rules in terms of prices and application periods are entirely defined a priori. On the other hand, for Dynamic Tariffs or Dynamic ToU Tariffs only general rules are set and then with some hours or days in advance the agent in charge of its management can declare that the price will be larger and will be applied to a specific number of hours.

The adoption of Dynamic Tariffs or Dynamic ToU Tariffs, has several barriers and challenges but some advantages can also be identified. Regarding the barriers and challenges it is important to mention that the demand is traditionally very inelastic not only regarding its total value but also in terms of its location along time. It is clear that part of this reduced elasticity is due to long term habits that can eventually be changed with price increases in some specific periods. However, in several cases, as happens with industrial processes, it is not possible or it is very difficult to reduce or to transfer demand to adjacent hours. This is either because of the process features, or because the shift is too costly. As a result, the impact of Dynamic Tariffs on demand will most likely be modest but can in any case introduce some flexibility in the system operation that should not be disregarded $[5,6,7,8]$. On the other hand, the implementation of these tariff options requires advanced metering equipment, as well as communication links between the DSO and the consumers in order to let them know with some hours or days in advance that a critical period is coming. Internet provides this link and regarding metering it is now common at least in several European countries EHV, $\mathrm{HV}$ and MV consumer meters provide hourly readings and telemetering capabilities. The progressive installation of smart metering in LV will, eventually, in the near future allow the extension of dynamic tariff programs to LV customers. Among the advantages of dynamic tariff options, we can consider the reduction of generation costs in peak periods or the impact on the market Social Welfare Function where these markets exist, the reduction of network losses 
and the cost of contracting reserves and the possible deferral of network expansion and reinforcement investments.

The main types of Dynamic Tariff schemes will be summarized below:

Real Time Pricing, RTP - in this case the tariffs, usually related to energy generation costs, vary on an hourly or a shorter term basis, namely reflecting the variation of the clearing prices in electricity markets. This is the most complex mechanism because it requires that the prices are communicated to the involved clients with some hours in advance so that they can adjust their demand reflecting the generation costs;

- Critical Peak Pricing, CPP - in CPP the prices are increased significantly (two to five times, for instance) to respond to particular events related, for instance to peak demand periods or to stressed network operation conditions. In this case, consumers know the rules of the program in terms of the events that may trigger a price increase, the multiplication factor to be applied to the tariffs, the maximum number of consecutive application hours, the yearly maximum number of application hours and the number of hours in advance they have to be notified of an event of this type. Compared with Static ToU Tariffs, implementing dynamic tariffs is more expensive as it is necessary to develop a mechanism to identify critical events in advance, to adapt billing systems and to communicate with consumers;

- Critical Peak Rebate, CPR - in this case, the tariffs are not increased but on the contrary consumers receive a bonus or a discount if some condition is accomplished. This can correspond, for instance, to a demand reduction regarding a reference level. This mechanism inherently protects the consumers because the price increase used in CPP is not present in this case;

- Direct Load Control, DLC - in DLC the supply of some loads of some consumers is directly controlled by the DSO that has the capacity to curtail them in case an event is expected. This resembles load interruptible contracts that exist in some countries and although having a different nature from the previous approaches, DLC can be seen as an extreme case application.

\section{B. International Experiences}

The application of Dynamic Tariffs is not widespread in the world and, on the contrary, implementation experiences are limited. Differently, there are several countries in which consumers can opt by Static ToU Tariffs. This is the case for Portugal, where LV customers can choose ToU tariffs with two or three different time periods, whereas MV, HV and EHV are all subject to a 4-period ToU scheme. In this way, tariffs reflect more closely the marginal generation costs or the average market clearing prices in the associated periods.

Regarding Dynamic Tariffs, or Dynamic ToU Tariffs, there are several experiences run by some utilities in the USA and some specific programs in Spain and France. In the USA, the Gulf Power Company runs the "Energy Select" program, which includes static ToU and CPP tariffs. The CPP program includes four energy prices (from low to critical) and the customers know the application periods of three of them. However, the utility can declare a critical period with some hours in advance in which the energy price is more than 10 times the price in the low period. These periods usually correspond to warm summer afternoons or cold winter mornings and each event has a duration from 1 to 2 hours. The Southern California Edison runs two programs called "Save Power Days" and "Summer Discount Plan". The first one is a CPR program in which consumers are notified by sms or email that a critical period is declared for the next day. These events are limited to 15 hours in a year, each one having a maximum of 4 hours and consumers receive an amount per $\mathrm{kWh}$ of demand that is reduced regarding the average values of the previous 5 days. The "Summer Discount Plan" is a DLC program in which the utility can disconnect air conditioning for a number of hours per day.

In Spain a new tariff mechanism was approved in April 2014, based on a RTP scheme. In this sense, the regulatory agency aims at more closely reflecting on the tariffs the market prices and contracting costs of ancillary services based on the day ahead market clearing prices obtained and also in reserve prices publicized by the TSO in the evening of each day for the next day.

Finally, in France in the scope of the TEMPO program small end users are informed on each day about the prices to be applied next day. This information is codified using three colors, blue for lower price days, white for intermediate and red for higher price days. Then, in each day, whatever color it has, there are two tariff periods - peak and off peak with different price levels. According to [9] the energy price in the peak period of red days is more than 5 times larger the price in the same period of a blue day.

\section{DESCRIPTION OF THE COST BENEFIT ANALYSIS}

The main objective of this study is the development of a Cost Benefit Analysis, CBA, to quantify the potential economic benefits coming from the introduction of dynamic tariffs in the Portuguese Tariff System. The success of the dynamic tariff framework relies on the proper identification of Critical Hours, that is, periods of highest network stress, for which the tariff will be increased to induce load transfer to neighboring hours. Therefore, the historical data from the year of 2014 was processed to identify the critical hours, both from a regional and a national perspective, and also per voltage level. Some patterns were identified, namely typical time location of critical hours and the months where most critical hours occur, for regional and national perspectives.

One of the possible benefits associated to the implementation of dynamic tariffs is related to the impacts on the electricity market Social Welfare Function (SWF). The use of the electricity market SWF modeled as the area between the cleared aggregated selling and buying curves for a particular hour is justified by the fact that in Portugal the traditional centralized cost based dispatch is substituted by a day ahead pool based market together with Spain. Moving load from critical hours to adjacent ones might lead to economic benefits as the peak and more costly generators become less needed during critical hours and the transferred 
load is scheduled to hours in which the market price is more reduced. As a result, the SWF gets reduced in the critical hours and increases in the adjacent hours due to the mentioned demand transfer. Therefore, the CBA analysis involved quantifying how the market SWF function on the critical and adjacent hours changes if a percentage of the demand is moved from the critical to the adjacent hours. This involves computing the SWF for the base demand in the critical and adjacent hours and then once again admitting the mentioned demand move. The difference of the SWF's values in these two situations is then used in the CBA analysis.

Another potential benefit from dynamic tariffs is the decrease in network power losses. From the historical demand data for 2014, and using loss profiles provided by ERSE, we estimated the power losses in 2014. These results were then used as reference to compare with the losses in case of shifting demand from critical hours to adjacent ones. The resulting benefit comes from the computed difference of losses between the reference and those where dynamic tariffs were implemented, being that difference multiplied by a cost reflecting the economical gain from reducing losses.

The investment of the Portuguese DSO is made under the assumption that the operation of the power system in the worst case scenario is guaranteed. Thus, the annual peak load is used as reference for investment planning. Dynamic Tariffs can have an active role in what concerns the reduction of peak load, which can result in investment postponement. Based on the equipment utilization factors (percentage of maximum flow in an equipment regarding its capacity) estimated for the horizon 2015-2030, namely for substation transformers and transmission lines, we assessed the impact of dynamic tariffs on postponing investment. We assumed that a network equipment investment was triggered when its utilization factor reached a level of $75 \%$ and the investment was commissioned 5 years afterwards. The investment needs for the reference scenario, i.e., without the dynamic tariffs, were calculated using typical investment costs provided by EDP Distribuição and adjusting the utilization factors along time using the expected demand growth rate. Afterwards, the investment cost was estimated again admitting that dynamic tariff were in place. As the yearly peak demand reduces when compared to the reference scenario there is a potential cost reduction due to investment postponements. In both cases, the investment Net Present Value along 2015-2030 was estimated using $6.75 \%$ for the discount rate, in line with the rate used by ERSE as regulatory rate of return on distribution network investment. The difference between the two cases is the economic benefit coming from the use of dynamic tariffs.

Finally, the impact on contracting secondary reserve was also considered. The possible gains would be dependent on the secondary reserve market price, as the reserve power to contract is larger in critical hours than in the adjacent ones. The possible economic benefits will come from the difference between the secondary reserve cost in the critical hours and in the adjacent ones from moving some demand.

The cost-benefit analysis considers not only the possible benefits listed above, but also the estimated implementation costs. EDP Distribuição identified costs related to the development of forecasting models for demand, distributed generation and critical hours on a regional and a voltage level basis, with programs to increase the awareness of customers, with communicating with consumers and with adaptation of the billing software to consider the new tariff options.

\section{RESUlTS OBTAINED FOR 2015-2030}

\section{A. Main Assumptions}

This study uses a 16-year horizon, from 2015 to 2030 . The starting point is based on observed values for 2014 regarding demand and distributed generation on a regional basis. The expected demand levels were provided by EDP Distribuição as well as typical equipment investment costs. These costs were updated using a $2.5 \%$ annual rate and a yearly discount rate of $6.75 \%$. The results presented below were computed under the assumption that 100 hours are identified as critical, as thus being subjected to price increase under the dynamic tariffs. According to typical elasticity values, we admitted that $5 \%$ of the total energy negotiated in the day-ahead electricity market (MIBEL) for the EHV, HV and MV levels could be moved to adjacent hours. The developed study also included simulations using values of $10 \%$ and $20 \%$ of demand transfer, namely for sensitivity purposes.

\section{B. Identification of Critical Hours}

One topic of this study was the identification of demand patterns by voltage level and region. This type of analysis makes one realize that an efficient implementation of dynamic tariffs in Portugal should consider a regional differentiation. We consider critical hours as the hours with highest network energy flows. In fact, some regions have most of the critical hours during the Winter season, while others have them on Summer months. Figures 1 and 2 show the distribution of the critical hours along the year and along the day in the region of Lisbon based on the aggregated demand of EHV, HV, MV and LV, if one considers the 100 , the 50 or the 20 hours of largest demand. Differently, in southern Portugal a larger number of critical hours occurs in the summer.

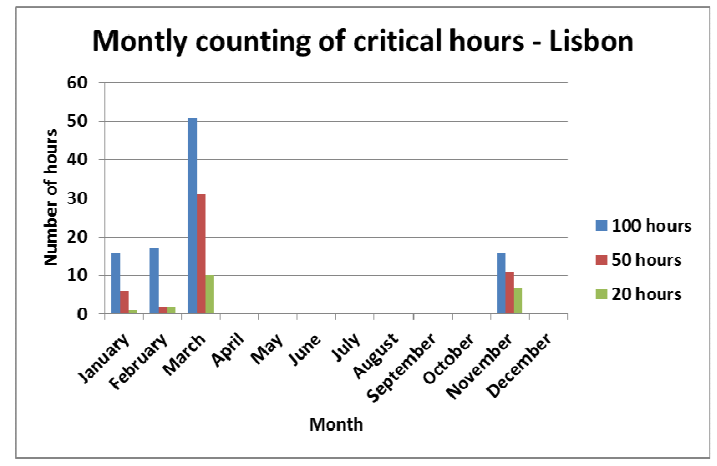

Figure 1. Montly counting of critical hours in the Lisbon region.

The analysis of critical hours for all voltage levels leads to the conclusion that LV is the greatest responsible for the stressful events that occur in the grid. Additionally, and depending on the region under analysis, the maximum load transfer potential in the upstream voltage levels not always coincide with those stressful moments in the LV grid. 


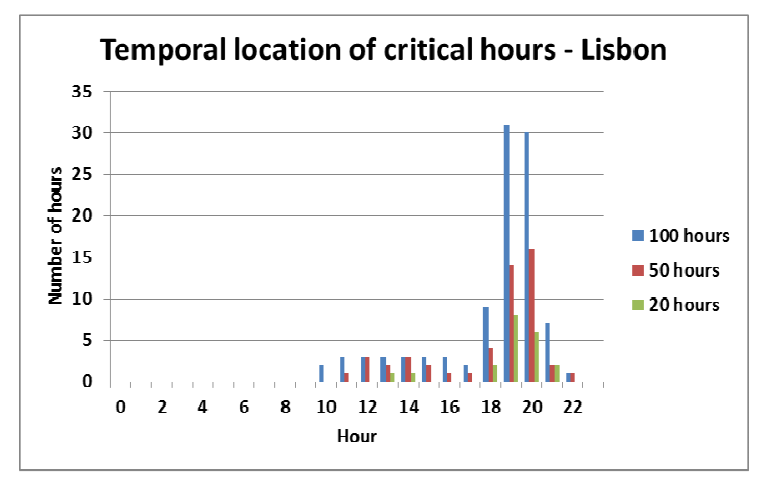

Figure 2. Temporal location of critical hours in the Lisbon region

\section{Results of the CBA Analysis}

The next paragraphs detail the simulations performed to estimate the benefits and costs over the 2015-2030 horizon. The partial results are omitted for confidentiality reasons.

The economic benefit regarding the market Social Welfare Function comes from the comparison of the SWF values of one hour and the adjacent ones when comparing situations with and without moving $5 \%$ of the EHV, HV and MV demand. This benefit was very found to be negligible namely in view of the amount estimated for the investment deferral.

Secondly, we estimated the energy loss differences in the critical and adjacent hours in EHV, HV and MV regarding the reference scenario. This was done admitting once again that $5 \%$ of the demand in these levels was shifted to adjacent hours and that the demand would increase till 2030 according to an evolution scenario provided by EDP Distribuição. As for the previous item, this benefit was also found negligible.

The benefit from deferring network investments is deeply dependent on the capability of reducing the annual peak load, as this value directly influences the investment needs. Once again, the investment needs in network assets were estimated in the reference scenario and compared with the amount if $5 \%$ of the demand in EHV, HV and MV was moved to adjacent hours. This benefit was estimated to be responsible for more than $98 \%$ of the total savings along the horizon.

The potential benefit from contracting secondary reserve depends on the market prices for that service in the critical hours being higher than in the adjacent ones. After analyzing public historical data from the secondary reserve market, it was concluded that the secondary reserve market prices do not follow a pattern consistent with the load level and are in fact more related with the forecasted amount of wind and PV generation. On the other hand, in most hours, bid prices are very close to each other, with differences of just some cents of euro. As a result, even if some demand was moved to another hour, the potential savings associated with contracting secondary reserve would be minimal.

EDP Distribuição estimated implementation costs that include consumption forecasting models, customer and retailer engagement programs, periodical information regarding demand patterns and the identification of critical days, and the design of a new billing structure. Part of these cost were allocated to the initial year and are related with implementation issues and software adaptations, while another part was spread along the horizon and brought back to the initial year using the discount rate of $6.75 \%$.

The final result of the Cost-Benefit Analysis comes from the sum of the estimated benefits subtracted by the implementation costs. Therefore, it is expected that the introduction of dynamic tariffs in the Portuguese Tariff System is able to produce a gain of around $7.140 \mathrm{k} €$ for the period 2015-2030, when compared to the reference scenario.

\section{CONCLUSIONS}

This paper reports the results of a consultancy study conducted by INESC TEC to EDP Distribuição to quantify the costs and benefits from introducing dynamic tariffs in the Portuguese Tariff System. The main results suggest that the benefits largely come from the possible deferral of network investments if a small part of peak demand is moved to adjacent hours. It should be mentioned that this study only involved demand supplied at EHV, $\mathrm{HV}$ and $\mathrm{MV}$, which are the levels required in the Portuguese Tariff code. On the other hand, it became clear that, although the dynamic tariff program can have general rules for the entire country, specific and regional tuning has to be considered given the differences in the location of the critical hours along the year when going from the North to the South of the country. Having these inputs in mind and with the experience gained so far, the next step will be the design of pilots to check these results, to better understand how much benefits the power system can collect from introducing this demand-response tool, and to possibly enable the formal approval of dynamic tariffs in Portugal.

\section{ACKNOWLEDGMENT}

The authors thank the Portuguese Energy Services Regulatory Agency, ERSE, namely to Dr. Pedro Verdelho and Dra. Isabel Apolinário, for all the useful discussions and suggestions received during the development of this work.

\section{REFERENCES}

[1] J. T. Saraiva, J. Fidalgo, R. A. Soares, R. B. Pinto, “Dynamic Tariffs Progress Report” (in Portuguese), INESC TEC, Porto, Portugal, November 2015

[2] A. K. David, Y. Z. Li, "Effect of Inter- Temporal Factors on the Real Time Pricing of Electricity”, IEEE Transactions on Power Systems, vol. 8, no. 1, pp. 44 - 52, February 1993.

[3] A. K. David, Y. C. Lee, "Dynamic Tariffs: Theory of Utility-consumer Interaction”, IEEE Transaction on Power Systems, vol. 4, no. 3, pp. 904 - 911, August 1989

[4] J. Rawlins, C. O’Connor, L. Fidao, "Time-of-Use Pricing", Carbon Trust, prepared to the Brazilian Regulatory Agency for the Electrical Energy, April 2012.

[5] M. Parsa Moghaddam, A. Abdollahi, M. Rashidinejad, "Flexible demand response programs modeling in competitive electricity markets", Applied Energy, vol. 88, issue 9, September 2011.

[6] A. Faruqui, D. Harris, R. Hledik, "Unlocking the $€ 53$ billion savings from smart meters in the EU: How increasing the adoption of dynamic tariffs could make or break the EU's smart grid investment”, Energy Policy, vol. 38, issue 10, October 2010.

[7] N. O'Connell, P. Pinson, H. Madsen, M. O'Malley, "Benefits and challenges of electrical demand response: A critical review", Renewable and Sustainable Energy Reviews, vol. 39, November 2014.

[8] Smart Energy Demand Coalition, "Mapping Demand Response in Europe Today", available in http://www.smartenergydemand.eu, assessed in January 2016.

[9] EDF, “Option TEMPO”, http://residential.edf.com/energy-athome/offers/electricity/tarif-bleu-56121.html. Assess in January 2016. 